\title{
Inverse Complex Function Dynamics of Ishikawa Iterates
}

\author{
Rajeshri Rana \\ Asst. Professor \\ Applied Science and Humanities \\ Department \\ G. B. Pant Engg. College, \\ Pauri Garhwal
}

\author{
Yashwant S. Chauhan \\ Asst. Professor \\ Computer Science \& Engg. \\ Department \\ G. B. Pant Engg. College, \\ Pauri Garhwal
}

\author{
Ashish Negi \\ Asst. Professor \\ Computer Science \& Engg. \\ Department \\ G. B. Pant Engg. College, \\ Pauri Garhwal
}

\begin{abstract}
We explore in this paper the dynamics of the inverse complex function using the Ishikawa iterates. The $z$ plane fractal images generated from the generalized transformation function $z \rightarrow\left(z^{n}+c\right)^{-1} \quad n \geq 2$ are analyzed.
\end{abstract}

Keywords: Complex dynamics, Relative Superior Mandelbrot Set, Relative Superior Julia set, Ishikawa Iteration.

\section{INTRODUCTION}

Several programs and papers have used escape-time methods to produce images of fractals based on the complex mapping $z \rightarrow\left(z^{n}+c\right)^{-1}$, where exponent $n$ is a positive integer. The fractals generated from the selfsquared function, $z \rightarrow z^{2}+c$ where $z$ and $c$ are complex quantities, have been studied extensively in the literature[I3, 4, 5, $6 \& 8$ 8. Recently, the generalized transformation function $z \rightarrow z^{-n}+c$ for positive integer values of $n$ has been considered by K. W. Shirriff [8]. The $z$ plane fractal images for the function $z_{n+1} \leftarrow z_{n}^{\alpha}+c$ for positive and negative, both integer and non-integer values of $n$ have been presented by Gujar et al. along with some conjectures about their visual characteristics $[4,5]$. In this paper, we consider the transformation of the function $z \rightarrow\left(z^{n}+c\right)^{-1}$, for $n \geq 2$, and analyze the $z$ plane fractal images generated from the iterations of this function using Ishikawa iteration procedure and analyze the drastic changes that occur in the visual characteristics of the images from $n=2,3,4, \ldots$

\section{PRELIMINEARIES}

The process of generating fractal images from $z \rightarrow\left(z^{n}+c\right)^{-1}$ is similar to the one employed for the self-squared function[10]. Briefly, this process consists of iterating these function upto $\mathrm{N}$ times. Starting from a value $z_{0}$ we obtain $z_{1}, z_{2}, z_{3}, z_{4}, \ldots$ by applying the transformation $z \rightarrow\left(z^{n}+c\right)^{-1}$

Definition2.1: Ishikawa Iteration [7]: Let $X$ be a subset of real or complex numbers and $f: X \rightarrow X$

for $x_{0} \in X$, we have the sequences $\left\{x_{n}\right\}$ and $\left\{y_{n}\right\}$ in $\mathrm{X}$ in the following manner:

$$
\begin{aligned}
& y_{n}=s_{n}^{\prime} f\left(x_{n}\right)+\left(1-s_{n}^{\prime}\right) x_{n} \\
& x_{n+1}=s_{n} f\left(y_{n}\right)+\left(1-s_{n}\right) x_{n}
\end{aligned}
$$

where $0 \leq s_{n}^{\prime} \leq 1, \quad 0 \leq s_{n} \leq 1$ and $\quad s_{n}^{\prime} \quad \& \quad s_{n}$ are both convergent to non zero number.

Definition 2.2: The sequences $x_{n}$ and $y_{n}$ constructed above is called Ishikawa sequences of iterations or Relative Superior sequences of iterates. We denote it by $R S O\left(x_{0}, s_{n}, s_{n}^{\prime}, t\right)$.

Notice that $\operatorname{RSO}\left(x_{0}, s_{n}, s_{n}^{\prime}, t\right)$ with $s_{n}^{\prime}=1$ is $S O\left(x_{0}, s_{n}, t\right)$ i.e. Mann's orbit and if we place $s_{n}=s_{n}^{\prime}=1$ then $R S O\left(x_{0}, s_{n}, s_{n}^{\prime}, t\right)$ reduces to $O\left(x_{0}, t\right)$.

$$
\text { We remark that Ishikawa orbit }
$$
$R S O\left(x_{0}, s_{n}, s_{n}^{\prime}, t\right)$ with $s_{n}^{\prime}=1 / 2$ is relative superior orbit.

Now we define Mandelbrot sets for function with respect to Ishikawa iterates. We call them as Relative Superior Mandelbrot sets

Definition 2.3: Relative Superior Mandelbrot set RSM for the function of the form $Q_{c}(z)=z^{n}+c$, where $n=1,2$, $3,4 \ldots$ is defined as the collection of $c \in C$ for which the orbit of 0 is bounded i.e.

$$
R S M=\left\{c \in C: Q_{c}^{k}(0): k=0,1,2 \ldots\right\} \text { is bounded. }
$$

In functional dynamics, we have existence of two different types of points. Points that leave the interval after a finite number are in stable set of infinity. Points that never leave the interval after any number of iterations have bounded orbits. So, an orbit is bounded if there exists a positive real number, such that the modulus of every point in the orbit is less than this number. 
The collection of points that are bounded, i.e. there exists $\mathrm{M}$, such that $\left|Q^{n}(z)\right| \leq M$, for all $n$, is called as a prisoner set while the collection of points that are in the stable set of infinity is called the escape set. Hence, the boundary of the prisoner set is simultaneously the boundary of escape set and that is Julia set for Q.

Definition 2.4: The set of points RSK whose orbits are bounded under relative superior iteration of the function $\mathrm{Q}$ (z) is called Relative Superior Julia sets. Relative Superior Julia set of Q is boundary of Julia set RSK.

2.1 Generation Process: The basic principle of generating fractals employs the iterative formula: $z_{n+1} \leftarrow f\left(z_{n}\right)$ where $z_{0}=$ the initial value of $\mathrm{z}$, and $z_{i}=$ the value of the complex quantity $z$ at the $i$ th iteration. For example, the Mandelbrot's self-squared function for generating fractals is: $f(z)=z^{2}+c$, where $z$ and $c$ are both complex quantities.

We propose the use of the transformation function $z \rightarrow\left(z^{n}+c\right)^{-1}$ for generating fractal images with respect to Ishikawa iterates, where $z$ and $c$ are the complex quantities and $n$ is a real number. Each of these fractal images is constructed as a two-dimensional array of pixels. Each pixel is represented by a pair of $(x, y)$ coordinates. The complex quantities $z$ and $c$ can be represented as:

$$
\begin{aligned}
& z=z_{x}+i z_{y} \\
& c=c_{x}+i c_{y}
\end{aligned}
$$

where $i=\sqrt{(-1)}$ and $z_{x}, c_{x}$ are the real parts and $z_{y} \& c_{y}$ are the imaginary parts of $z$ and $c$, respectively. The pixel coordinates $(x, y)$ may be associated with $\left(c_{x}, c_{y}\right)$ or $\left(z_{x}, z_{y}\right)$.

Based on this concept, the fractal images can be classified as follows: (a) c-plane fractals, wherein $(x, y)$ is a function of $\left(c_{x}, c_{y}\right)$

(b) z-plane fractals, wherein $(x, y)$ is a function of $\left(z_{x}, z_{y}\right)$.

In the literature, the fractals for $n=2$ in $z$ plane are termed as the Mandelbrot set while the fractals for $n=2$ in $c$ plane are known as Julia sets [10].

2.2 Generating the fractals: Fractals have been generated from $z \rightarrow z^{-n}+c$ using escape-time techniques, for example by Gujar etal.[4, 5] and Glynn [6].
We have used in this paper escape time criteria of Relative Superior Ishikawa iterates for function $z \rightarrow\left(z^{n}+c\right)^{-1}$.

Escape Criterion for Quadratics: Suppose that $|z|>\max \left\{|c|, 2 / s, 2 / s^{\prime}\right\}, \quad$ then $\left|z_{n}\right|>(1+\lambda)^{n}|z|$ and $\left|z_{n}\right| \rightarrow \infty$ as $n \rightarrow \infty$.So, $|z| \geq|c|$ and $|z|>2 / s$ as well as $|z|>2 / s^{\prime}$ shows the escape criteria for quadratics.

Escape Criterion for Cubics: Suppose $|z|>\max \left\{|b|,(|a|+2 / s)^{1 / 2},\left(|a|+2 / s^{\prime}\right)^{1 / 2}\right\}$

then $\left|z_{n}\right| \rightarrow \infty$ as $n \rightarrow \infty$. This gives an escape criterion for cubic polynomials

General Escape Criterion: Consider $|z|>\max \left\{|c|,(2 / s)^{1 / n},\left(2 / s^{\prime}\right)^{1 / n}\right\} \quad$ then $\left|z_{n}\right| \rightarrow \infty$ as $n \rightarrow \infty$ is the escape criterion. (Escape Criterion derived in [12]).

Note that the initial value $z_{0}$ should be infinity, since infinity is the critical point of $z \rightarrow\left(z^{n}+c\right)^{-1}$. However instead of starting with $z_{0}=$ infinity, it is simpler to start with $z_{1}=c$, which yields the same result. (A critical point of $\mathrm{z} \rightarrow \mathrm{F}(\mathrm{z})+\mathrm{c}$ is a point where $\mathrm{F}^{\prime}(z)=0$ ). The role of critical points is explained in [1].

\section{GEOMETRY OF RELATIVE SUPERIOR MANDELBROT SETS AND RELATIVE SUPERIOR JULIA SETS:}

The fractals generated from the equation $z \rightarrow\left(z^{n}+c\right)^{-1}$ possesses rotational as well as reflection symmetry. As conjectured by Gujar and Bhavsar in [4], the fractals generated with the exponent $n$ are $(n+1)$ way rotationally symmetric.

\section{Relative Superior Mandelbrot sets:}

- Here we notice that the number of wings in the Relative Superior Mandelbrot sets of inverse function is $n+1$, where $n$ is the power of $z \rightarrow\left(z^{n}+c\right)^{-1}$.

- $\quad$ As the value of $s$ tend to 1 and $s^{\prime}$ tends to 1 , the Relative Superior Mandelbrot sets of inverse function converts to the general Mandelbrot sets of inverse function, hence we can say that the Relative Superior Mandelbrot sets of inverse function is the general case of the usual Mandelbrot sets of inverse function.

- We observe in the $z$ plane that Relative Superior Mandelbrot sets looks as the lace like structures having mini circles containing different colors, along each wing. 
-For quadratic function, we have triangular like structures representing symmetry along $\mathrm{X}$ axis. For Cubic function, we have symmetry along both $\mathrm{X}$ and $\mathrm{Y}$-axis which also represents reflection as well as rotational symmetry. Similarly for the bi quadratic function, we have reflection as well as rotational symmetry.

\section{Relative Superior Julia sets:}

- Geometrical analysis of the Relative Superior Julia sets of inverse function shows that the boundary of the fixed point region forms a $(\boldsymbol{n}+\mathbf{1})$ hypocycloid $(A$ hypocycloid is a curve formed by rolling a smaller circle inside a larger circle and tracing a fixed point on the circumference of the smaller circle). The radius of the outer fixed circle for hypocycloid can be computed as $|z|+\left|z^{-n}\right|$, where $\quad \mathrm{z}$ satisfies the condition $|z|>n^{1 /(n+1)}$, resulting in a radius of $(n+1) n^{-n /(n+1)}$. The radius of inner moving circle is $\left|z^{-n}\right|$ yielding $n^{-n /(n+1)}$.

- For each value of $c$, we can iterate the mapping and test if the resulting sequence of $\mathrm{z}$ approaches a cycle. Points leading to a cycle can be colored according to the length of the cycle and the points that never enter the cycle but wander chaotically are colored. Figures[All figures of 6.1, $6.2 \& 6.3]$ shows this process. Here white color regions represent stable points while black colored regions represent unstable points.

- Relative Superior Julia sets of inverse function for quadratic function shows triangular symmetry. For cubic function Relative Superior Julia sets shows symmetry along $\mathrm{X}$ and $\mathrm{Y}$ axes both. Moreover this function also describes reflection and rotational symmetry. The biquadratic function shows us the fascinating results. Here we have central planet with satellite like structures obtained that represents reflection and rotational symmetry.

\section{FIXED POINTS}

4.1 Fixed points of quadratic polynomial

Table 1: Orbit of $F(z)$ at $\mathbf{s}=\mathbf{1}$ and $\mathbf{s}^{\prime}=\mathbf{1}$ for $\left(\mathrm{z}_{0}=-\mathbf{0 . 0 6 8 7 0 3 6 9 3 3 2}+\mathbf{0 . 0 4 4 1 4 0 1 5 6 1 5 i}\right)$

\begin{tabular}{|c|c|c|c|}
\hline $\begin{array}{l}\text { Number of } \\
\text { iteration } i\end{array}$ & $|F(z)|$ & $\begin{array}{l}\text { Number of } \\
\text { iteration } i\end{array}$ & $|F(z)|$ \\
\hline 1 & 0.081661 & 11 & 0.24478 \\
\hline 2 & 0.24251 & 12 & 0.24468 \\
\hline 3 & 0.27198 & 13 & 0.24464 \\
\hline 4 & 0.24936 & 14 & 0.24467 \\
\hline 5 & 0.23735 & 15 & 0.24468 \\
\hline
\end{tabular}

\begin{tabular}{|c|c|c|c|}
\hline 6 & 0.24377 & 16 & 0.24467 \\
\hline 7 & 0.24647 & 17 & 0.24467 \\
\hline 8 & 0.24491 & 18 & 0.24467 \\
\hline 9 & 0.24422 & 19 & 0.24467 \\
\hline 10 & 0.24461 & 20 & 0.24467 \\
\hline
\end{tabular}

Here we observe that the value converges to a fixed point after 16 iterations

Figure 1. Orbit of $F(z)$ at $\mathbf{s}=\mathbf{1}$ and $\mathbf{s}^{\prime}=\mathbf{1}$ for $\left(\mathrm{z}_{0}=-\mathbf{0 . 0 6 8 7 0 3 6 9 3 3 2}+\mathbf{0 . 0 4 4 1 4 0 1 5 6 1 5 i}\right)$

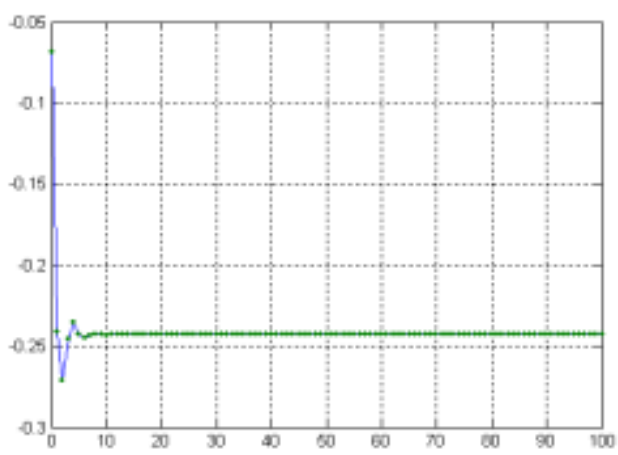

Table 2: Orbit of $\mathrm{F}(\mathrm{z})$ at $\mathbf{s}=\mathbf{0 . 5}$ and $\mathbf{s}^{\prime}=\mathbf{0 . 1}$ for $\left(z_{0}=\mathbf{- 0 . 0 1 1 9 2 2 8 8 6 3 9 + 0 . 0 1 0 4 2 3 7 9 6 6 8 i ~}\right)$

\begin{tabular}{|c|c|c|c|}
\hline $\begin{array}{l}\text { Number of } \\
\text { iteration } \mathrm{i}\end{array}$ & $|\mathrm{F}(\mathrm{z})|$ & $\begin{array}{l}\text { Number of } \\
\text { iteration } \mathrm{i}\end{array}$ & $|\mathrm{F}(\mathrm{z})|$ \\
\hline 1 & 0.015837 & 6 & 0.85943 \\
\hline 2 & 0.98458 & 7 & 0.85943 \\
\hline 3 & 0.86429 & 8 & 0.85942 \\
\hline 4 & 0.85883 & 9 & 0.85942 \\
\hline 5 & 0.85933 & 10 & 0.85942 \\
\hline
\end{tabular}

Here we observe that the value converges to a fixed point after 08 iterations

Figure 2. Orbit of $F(z)$ at $s^{=0.5}$ and $s^{\prime}=0.1$ for $\left(z_{0}=-\mathbf{0 . 0 1 1 9 2 2 8 8 6 3 9}+\mathbf{0 . 0 1 0 4 2 3 7 9 6 6 8 i}\right)$

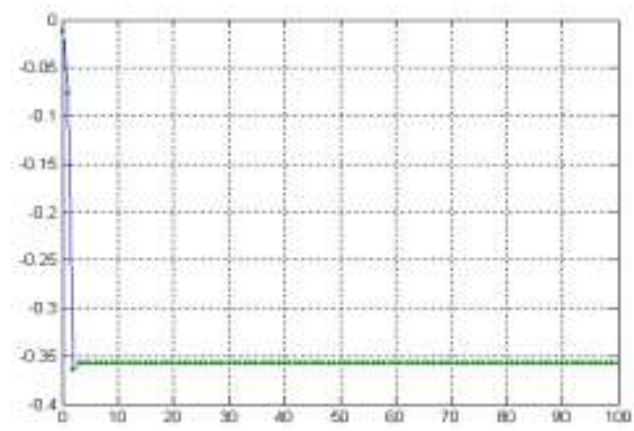

Table 3: Orbit of $\mathrm{F}(\mathrm{z})$ at $\mathrm{s}=\mathbf{0 . 5}$ and $\mathrm{s}^{\prime}=\mathbf{0 . 4}$ for $\left(z_{0}=\mathbf{- 0 . 0 0 2 1 6 9 1 9 4 0 7 9 + 0 . 0 4 6 5 7 5 0 7 5 6 i}\right)$

\begin{tabular}{|c|c|c|c|}
\hline $\begin{array}{l}\text { Number of } \\
\text { iteration } \mathrm{i}\end{array}$ & $|\mathrm{F}(\mathrm{z})|$ & $\begin{array}{l}\text { Number of } \\
\text { iteration } \mathrm{i}\end{array}$ & $|\mathrm{F}(\mathrm{z})|$ \\
\hline 1 & 0.046626 & 11 & 0.85953 \\
\hline 2 & 0.62449 & 12 & 0.85947 \\
\hline 3 & 0.82831 & 13 & 0.85944 \\
\hline 4 & 0.85955 & 14 & 0.85943 \\
\hline 5 & 0.86349 & 15 & 0.85943 \\
\hline
\end{tabular}




\begin{tabular}{|c|c|c|c|}
\hline 6 & 0.8626 & 16 & 0.85942 \\
\hline 7 & 0.86131 & 17 & 0.85942 \\
\hline 8 & 0.86042 & 18 & 0.85942 \\
\hline 9 & 0.85991 & 19 & 0.85942 \\
\hline 10 & 0.85965 & 20 & 0.85942 \\
\hline
\end{tabular}

Here the value converges to a fixed point after 16 iterations

Figure 3. Orbit of $F(z)$ at $s=0.5$ and $s^{\prime}=0.4$ for $\left(z_{0}=-\mathbf{0 . 0 0 2 1 6 9 1 9 4 0 7 9}+\mathbf{0 . 0 4 6 5 7 5 0 7 5 6 i}\right)$

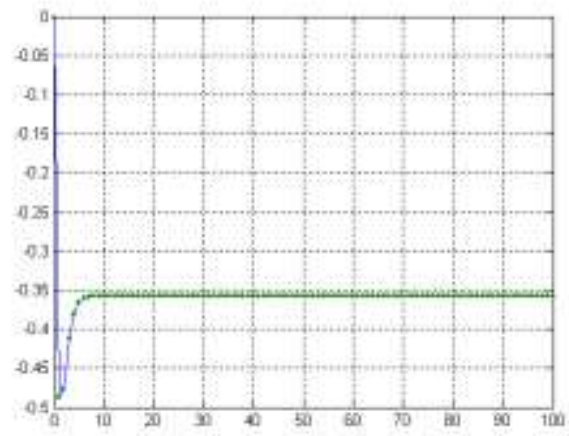

Table 4 Orbit of $F(z)$ at $s=0.8$ and $s^{\prime}=0.4$ for $\left(z_{0}=\mathbf{- 0 . 0 1 6 0 5 9 5 3 5 7 9 + 0 . 0 1 8 7 9 4 3 9 2 1 7 i ~}\right)$

\begin{tabular}{|l|l|l|l|}
\hline $\begin{array}{l}\text { Number of } \\
\text { iteration } \mathrm{i}\end{array}$ & $|\mathrm{F}(\mathrm{z})|$ & $\begin{array}{l}\text { Number of } \\
\text { iteration } \mathrm{i}\end{array}$ & $|\mathrm{F}(\mathrm{z})|$ \\
\hline 1 & 0.024721 & 7 & 0.85938 \\
\hline 2 & 1.292 & 8 & 0.85943 \\
\hline 3 & 0.76997 & 9 & 0.85942 \\
\hline 4 & 0.87184 & 10 & 0.85942 \\
\hline 5 & 0.85748 & 11 & 0.85942 \\
\hline 6 & 0.85972 & 12 & 0.85942 \\
\hline
\end{tabular}

Here the value converges to a fixed point after 09 iterations

Figure 4. Orbit of $F(z)$ at $s=0.8$ and $s '=0.4$ for $\left(\mathrm{z}_{0}=\mathbf{- 0 . 0 1 6 0 5 9 5 3 5 7 9 + 0 . 0 1 8 7 9 4 3 9 2 1 7 i}\right)$

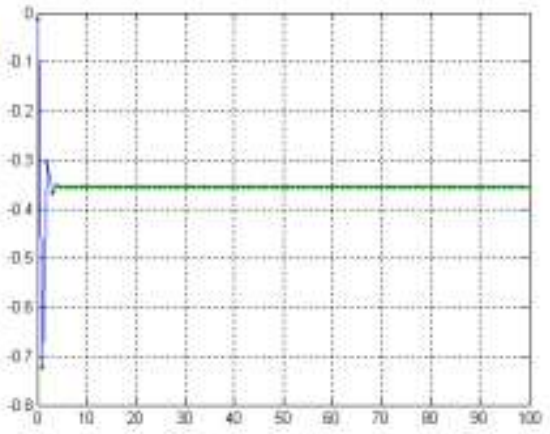

4.2 Fixed points of Cubic polynomial

Table 1: Orbit of $F(z)$ at $s=1$ and $s^{\prime}=1$ for $\left(\mathrm{z}_{0}=0.01410390589+0.04994371026 \mathrm{i}\right)$

\begin{tabular}{|l|l|l|l|}
\hline $\begin{array}{l}\text { Number of } \\
\text { iteration } i\end{array}$ & $|\mathrm{~F}(\mathrm{z})|$ & $\begin{array}{l}\text { Number of } \\
\text { iteration } \mathrm{i}\end{array}$ & $|\mathrm{F}(\mathrm{z})|$ \\
\hline 1 & 0.051897 & 5 & 0.11876 \\
\hline 2 & 0.11758 & 6 & 0.11876 \\
\hline 3 & 0.11873 & 7 & 0.11876 \\
\hline
\end{tabular}

\begin{tabular}{l|l|l|l|}
\hline 4 & 0.11876 & 8 & 0.11876 \\
\hline $\begin{array}{l}\text { Here we observe that the value converges to a fixed } \\
\text { point after 04 iterations }\end{array}$
\end{tabular}

Figure 1. Orbit of $F(z)$ at $s=1$ and $s^{\prime}=1$ for $\left(\mathrm{z}_{0}=\mathbf{0 . 0 1 4 1 0 3 9 0 5 8 9 + 0 . 0 4 9 9 4 3 7 1 0 2 6 i )}\right.$

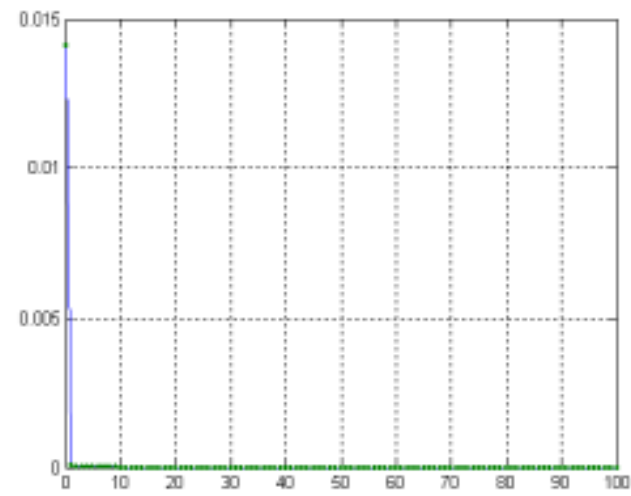

Table 2: Orbit of $\mathrm{F}(\mathrm{z})$ at $\mathrm{s}=\mathbf{0 . 5}$ and $\mathrm{s}^{\prime}=\mathbf{0 . 1}$ for $\left(\mathrm{z}_{0} 0.00888346751+0.01650347336 \mathrm{i}\right)$

\begin{tabular}{|l|l|l|l|}
\hline $\begin{array}{l}\text { Number of } \\
\text { iteration i }\end{array}$ & $\mid \mathrm{F}(\mathrm{z})$ & $\begin{array}{l}\text { Number of } \\
\text { iteration i }\end{array}$ & $|\mathrm{F}(\mathrm{z})|$ \\
\hline 1 & 0.018742 & 6 & 0.86749 \\
\hline 2 & 0.97928 & 7 & 0.86747 \\
\hline 3 & 0.85738 & 8 & 0.86747 \\
\hline 4 & 0.86871 & 9 & 0.86747 \\
\hline 5 & 0.86732 & 10 & 0.86747 \\
\hline
\end{tabular}

Here we observe that the value converges to a fixed point after 07 iterations

Figure 2 Orbit of $F(z)$ at $\mathbf{s}=\mathbf{0 . 5}$ and $\mathbf{s}^{\prime}=\mathbf{0 . 1}$ for $\left(z_{0} 0.00888346751+0.01650347336 i\right)$

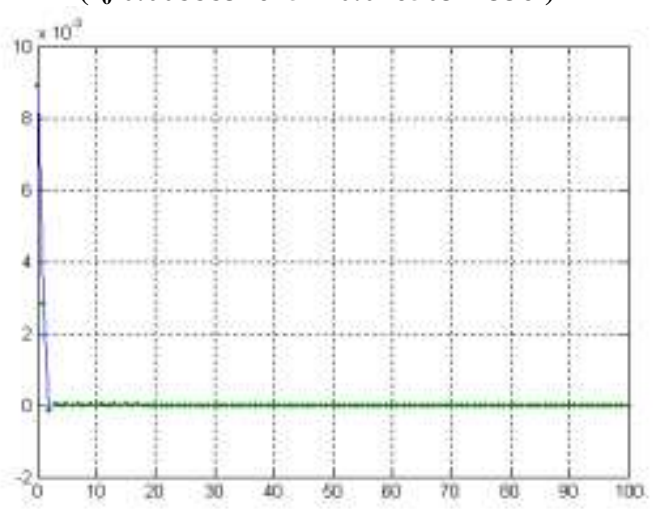

Table 3: Orbit of $\mathrm{F}(\mathrm{z})$ at $\mathbf{s}=\mathbf{0 . 5}$ and $\mathbf{s}^{\prime}=\mathbf{0 . 3}$ for $\left(\mathrm{z}_{0}-\mathbf{- 0 . 0 2 0 5 1 4 3 3 0 6 7 + 0 . 0 1 2 6 9 6 1 8 2 7 7 6 \mathrm { i } )}\right.$

\begin{tabular}{|l|l|l|l|}
\hline $\begin{array}{l}\text { Number of } \\
\text { iteration } \mathrm{i}\end{array}$ & $|\mathrm{F}(\mathrm{z})|$ & $\begin{array}{l}\text { Number of } \\
\text { iteration } \mathrm{i}\end{array}$ & $|\mathrm{F}(\mathrm{z})|$ \\
\hline 1 & 0.024125 & 8 & 0.86716 \\
\hline 2 & 0.7014 & 9 & 0.86736 \\
\hline 3 & 0.803 & 10 & 0.86743 \\
\hline 4 & 0.84433 & 11 & 0.86746 \\
\hline
\end{tabular}




\begin{tabular}{|l|l|l|l|}
\hline 5 & 0.85947 & 12 & 0.86747 \\
\hline 6 & 0.86474 & 13 & 0.86747 \\
\hline 7 & 0.86655 & 14 & 0.86747 \\
\hline
\end{tabular}

Here the value converges to a fixed point after 12 iterations

Figure 3. Orbit of $F(z)$ at $\mathbf{s}=\mathbf{0 . 5}$ and $s^{\prime}=0.3$ for $\left(\mathrm{z}_{0}-\mathbf{- 0 . 0 2 0 5 1 4 3 3 0 6 7}+\mathbf{0 . 0 1 2 6 9 6 1 8 2 7 7 6 i}\right)$

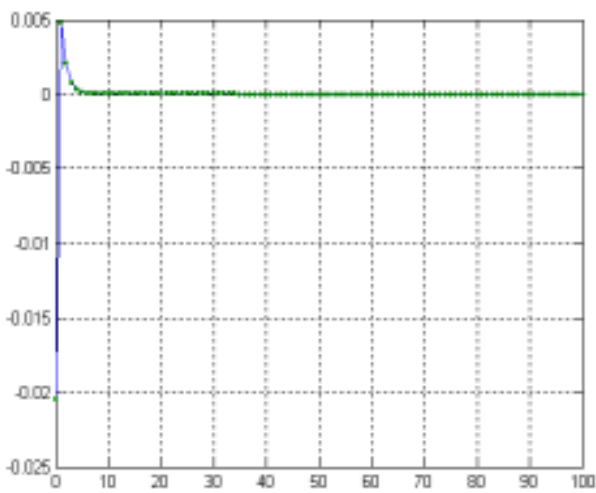

Table 4 Orbit of $F(z)$ at $s=0.8$ and $s^{\prime}=0.3$ for $\left(z_{0}=-\mathbf{0 . 0 2 0 5 1 4 3 3 0 6 7 + 0 . 0 1 7 4 6 7 3 0 5 1 6 i )}\right.$

\begin{tabular}{|l|l|l|l|}
\hline $\begin{array}{l}\text { Number of } \\
\text { iteration } \mathrm{i}\end{array}$ & $|\mathrm{F}(\mathrm{z})|$ & $\begin{array}{l}\text { Number of } \\
\text { iteration } \mathrm{i}\end{array}$ & $|\mathrm{F}(\mathrm{z})|$ \\
\hline 1 & 0.026943 & 6 & 0.86748 \\
\hline 2 & 1.1347 & 7 & 0.86747 \\
\hline 3 & 0.81968 & 8 & 0.86747 \\
\hline 4 & 0.86911 & 9 & 0.86747 \\
\hline 5 & 0.86737 & 10 & 0.86747 \\
\hline
\end{tabular}

Here the value converges to a fixed point after 07 iterations

Figure 4. 4 Orbit of $F(z)$ at $s=0.8$ and $s^{\prime}=0.3$ for $\left(z_{0}=-\mathbf{0 . 0 2 0 5 1 4 3 3 0 6 7 + 0 . 0 1 7 4 6 7 3 0 5 1 6 i )}\right.$

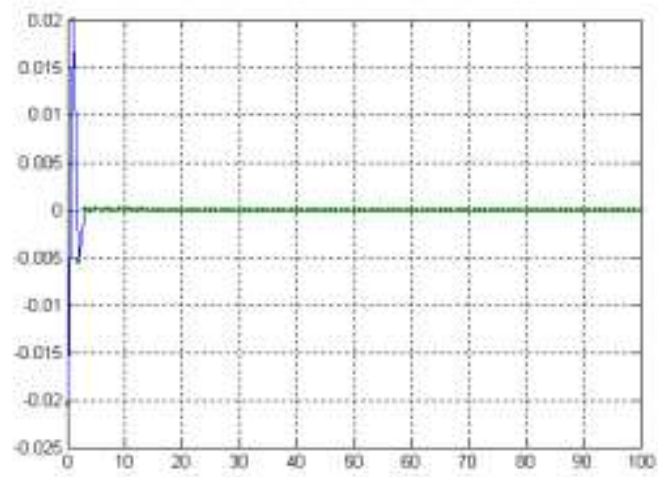

\subsection{Fixed points of $\mathrm{Bi}$-quadratic polynomial}

Table 1: Orbit of $F(z)$ at $s=1$ and $s^{\prime}=1$ for $\left(\mathrm{z}_{0}=\mathbf{- \mathbf { 0 . 6 4 2 4 7 3 9 8 8 8 } - 0 . 5 1 4 6 5 5 8 7 9 9 i )}\right.$

\begin{tabular}{|l|l|l|l|}
\hline $\begin{array}{l}\text { Number of } \\
\text { iteration } i\end{array}$ & $|\mathrm{~F}(\mathrm{z})|$ & $\begin{array}{l}\text { Number of } \\
\text { iteration } \mathrm{i}\end{array}$ & $|\mathrm{F}(\mathrm{z})|$ \\
\hline 1 & 0.82319 & 5 & 0.062468 \\
\hline 2 & 0.52011 & 6 & 0.062468 \\
\hline
\end{tabular}

\begin{tabular}{|l|l|l|l|}
\hline 3 & 0.075665 & 7 & 0.062468 \\
\hline 4 & 0.062484 & 8 & 0.062468 \\
\hline
\end{tabular}

Here we observe that the value converges to a fixed point after 05 iterations

Figure 1 Orbit of $F(z)$ at $s=1$ and $s^{\prime}=1$ for $\left(\mathrm{z}_{0}=\mathbf{- 0 . 6 4 2 4 7 3 9 8 8 8 - 0 . 5 1 4 6 5 5 8 7 9 9 i}\right)$

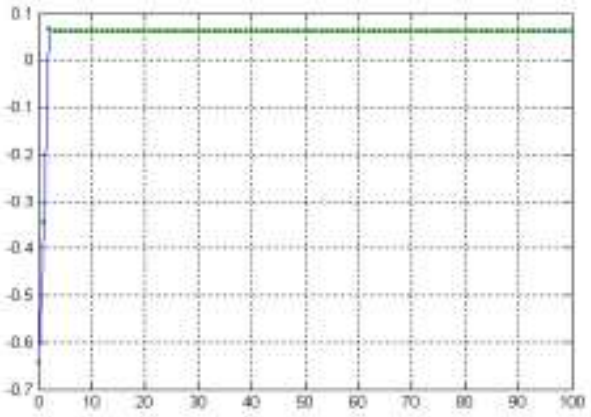

Table 2: Orbit of $\mathrm{F}(\mathrm{z})$ at $\mathrm{s}=\mathbf{0 . 5}$ and $\mathrm{s}^{\prime}=\mathbf{0 . 1}$ for $\left(\mathrm{z}_{0}=\mathbf{- 0 . 0 1 5 7 3 7 6 9 4 9 4 + 0 . 0 3 6 7 8 8 7 1 8 9 7 i}\right)$

\begin{tabular}{|l|l|l|l|}
\hline $\begin{array}{l}\text { Number of } \\
\text { iteration i }\end{array}$ & $|\mathrm{F}(\mathrm{z})|$ & $\begin{array}{l}\text { Number of } \\
\text { iteration } \mathrm{i}\end{array}$ & $|\mathrm{F}(\mathrm{z})|$ \\
\hline 1 & 0.040014 & 8 & 0.8968 \\
\hline 2 & 0.98215 & 9 & 0.89704 \\
\hline 3 & 0.90556 & 10 & 0.89699 \\
\hline 4 & 0.88426 & 11 & 0.89699 \\
\hline 5 & 0.90308 & 12 & 0.89699 \\
\hline 6 & 0.89476 & 13 & 0.89699 \\
\hline 7 & 0.8977 & 14 & 0.89699 \\
\hline
\end{tabular}

Here we observe that the value converges to a fixed point after 10 iterations

Figure 2. : Orbit of $\mathrm{F}(\mathrm{z})$ at $\mathbf{s}=\mathbf{0 . 5}$ and $\mathbf{s}^{\prime}=\mathbf{0 . 1}$ for $\left(z_{0}=-0.01573769494+0.03678871897 i\right)$

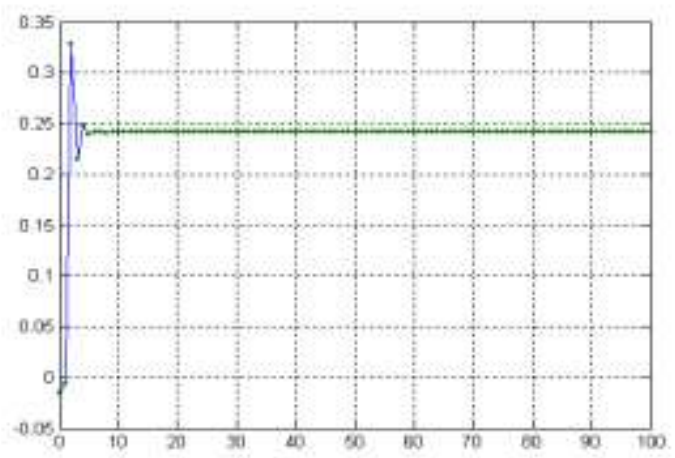

Table 3: Orbit of $\mathrm{F}(\mathrm{z})$ at $\mathrm{s}=\mathbf{0 . 5}$ and $\mathbf{s}^{\prime}=\mathbf{0 . 3}$ for $\left(\mathrm{z}_{0}=\mathbf{- 0 . 0 2 2 7 1 4 4 3 3 7}+\mathbf{0 . 0 4 3 7 6 5 4 5 7 7 3 i}\right)$

\begin{tabular}{|l|l|l|l|}
\hline $\begin{array}{l}\text { Number of } \\
\text { iteration i }\end{array}$ & $|\mathrm{F}(\mathrm{z})|$ & $\begin{array}{l}\text { Number of } \\
\text { iteration } \mathrm{i}\end{array}$ & $|\mathrm{F}(\mathrm{z})|$ \\
\hline 1 & 0.049309 & 11 & 0.89688 \\
\hline 2 & 0.97756 & 12 & 0.89695 \\
\hline 3 & 0.92815 & 13 & 0.89698 \\
\hline 4 & 0.90685 & 14 & 0.89699 \\
\hline
\end{tabular}




\begin{tabular}{|l|l|l|l|}
\hline 5 & 0.89864 & 15 & 0.897 \\
\hline 6 & 0.89615 & 16 & 0.897 \\
\hline 7 & 0.89585 & 17 & 0.89699 \\
\hline 8 & 0.89616 & 18 & 0.89699 \\
\hline 9 & 0.89651 & 19 & 0.89699 \\
\hline 10 & 0.89675 & 20 & 0.89699 \\
\hline
\end{tabular}

Here the value converges to a fixed point after 17 iterations

Figure 3. Orbit of $\mathrm{F}(\mathrm{z})$ at $\mathrm{s}=\mathbf{0 . 5}$ and $\mathrm{s}^{\prime}=\mathbf{0 . 3}$ for $\left(z_{0}=-\mathbf{0 . 0 2 2 7 1 4 4 3 3 7}+0.04376545773 i\right)$

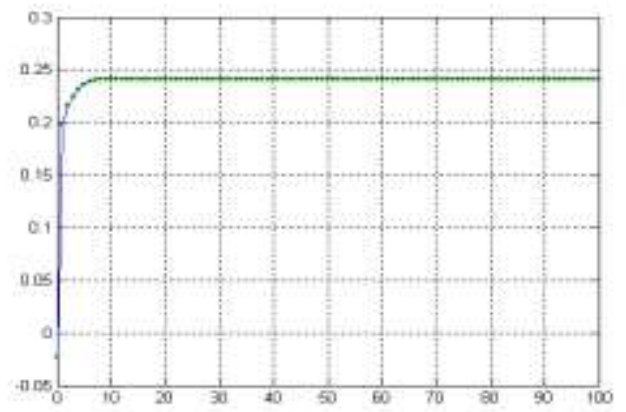

Table 4 Orbit of $F(z)$ at $s=0.8$ and $s^{\prime}=0.3$ for $\left(\mathrm{z}_{0}=\mathbf{- 0 . 0 0 8 7 6 0 9 5 6 1 7 7 + 0 . 0 5 0 7 4 2 1 9 6 4 9 i )}\right.$

\begin{tabular}{|l|l|l|l|}
\hline $\begin{array}{l}\text { Number of } \\
\text { iteration } \mathrm{i}\end{array}$ & $|\mathrm{F}(\mathrm{z})|$ & $\begin{array}{l}\text { Number of } \\
\text { iteration } \mathrm{i}\end{array}$ & $|\mathrm{F}(\mathrm{z})|$ \\
\hline 1 & 0.051493 & 9 & 0.897 \\
\hline 2 & 1.5711 & 10 & 0.89704 \\
\hline 3 & 0.68507 & 11 & 0.897 \\
\hline 4 & 0.91356 & 12 & 0.89699 \\
\hline 5 & 0.93446 & 13 & 0.89699 \\
\hline 6 & 0.89932 & 14 & 0.89699 \\
\hline 7 & 0.89522 & 15 & 0.89699 \\
\hline 8 & 0.8964 & 16 & 0.89699 \\
\hline
\end{tabular}

Here the value converges to a fixed point after 21 iterations

Figure 4. Orbit of $F(z)$ at $\mathbf{s}=\mathbf{0 . 8}$ and $\mathrm{s}^{\prime}=\mathbf{0 . 3}$ for $\left(\mathrm{z}_{0}=\mathbf{- 0 . 0 0 8 7 6 0 9 5 6 1 7 7 + 0 . 0 5 0 7 4 2 1 9 6 4 9 i )}\right.$

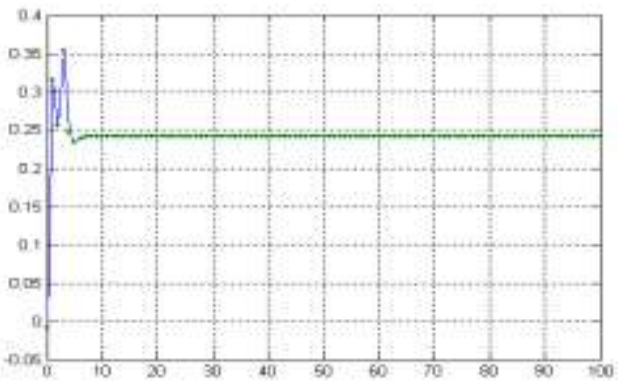

\section{GENERATION OF RELATIVE} SUPERIOR MANDELBROT SETS

We present here some Relative Superior Mandelbrot sets for quadratic, cubic and biquadratic function.
5.1 Relative Superior Mandelbrot Sets for Quadratic function:

Figure 1: Relative Superior Mandelbrot Set for $s=s^{\prime}=1$

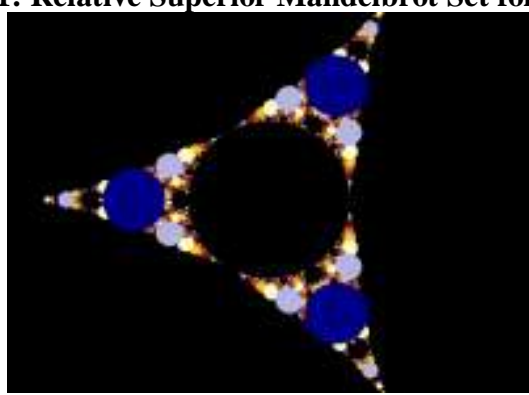

Figure 2: Relative Superior Mandelbrot Set for $s=0.8$,

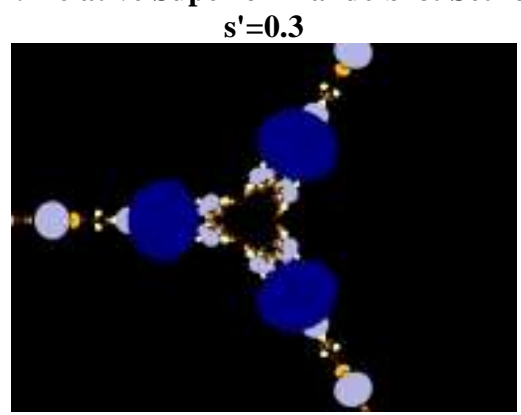

Figure 3: Relative Superior Mandelbrot Set for

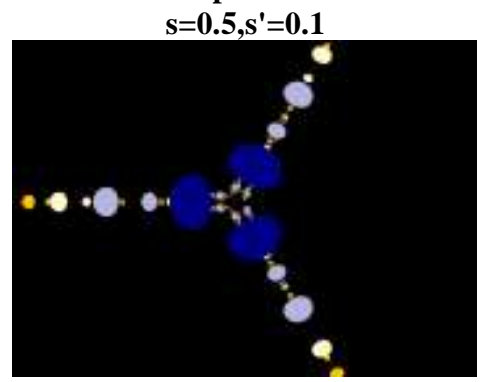

5.2 Relative Superior Mandelbrot Sets for Cubic function:

Figure 1: Relative Superior Mandelbrot Set for $s=s^{\prime}=1$

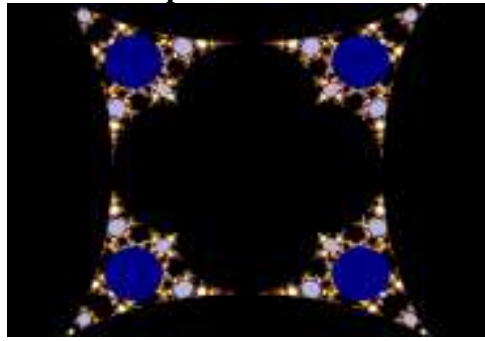

Figure 2: Relative Superior Mandelbrot Set for $\mathrm{s}=\mathbf{0 . 8 \text { , }}$ $s^{\prime}=0.3$ 


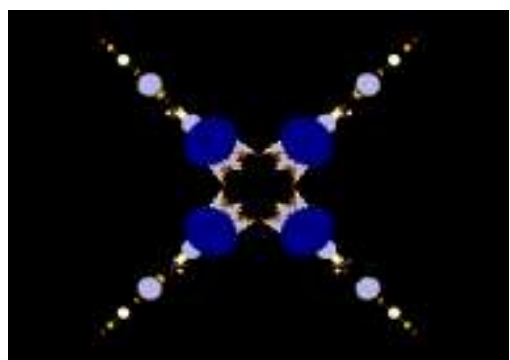

Figure 3: Relative Superior Mandelbrot Set $s=0.5$, $\mathbf{s}^{\prime}=\mathbf{0 . 1}$

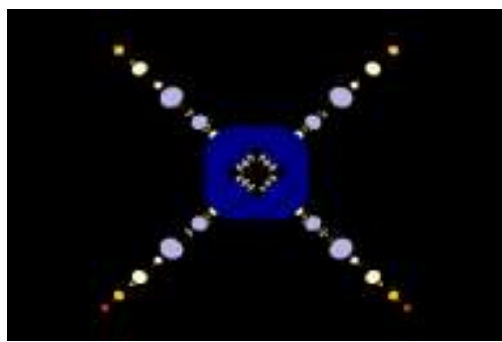

5.3 Relative Superior Mandelbrot Sets for Biquadratic function:

Figure 1: Relative Superior Mandelbrot Set for $s=s^{\prime}=1$

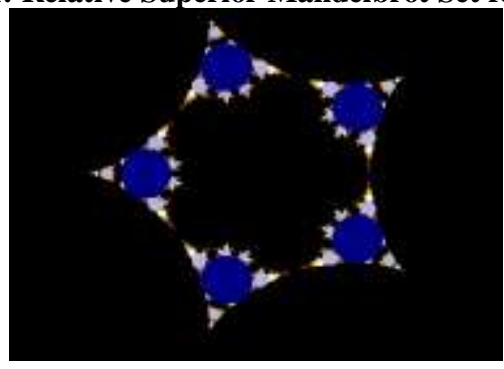

Figure 2: Relative Superior Mandelbrot Set for $s=0.5$,

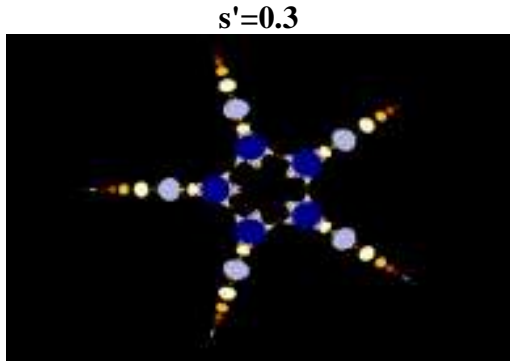

Figure 3: Relative Superior Mandelbrot Set for $\mathrm{s}=\mathbf{0 . 5}$, $\mathbf{s}^{\prime}=\mathbf{0 . 1}$

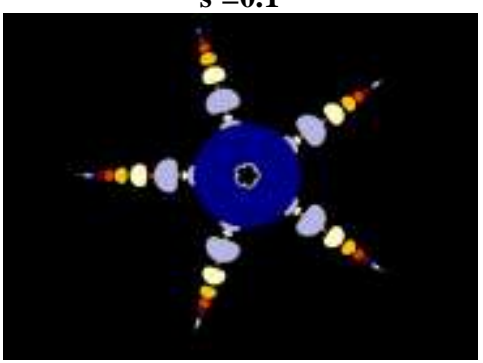

\section{GENERATION OF RELATIVE} SUPERIOR JULIA SETS:

6.1 Relative Superior Julia sets for Quadratic:

Figure 1: Relative Superior Julia Set for $s=0.5$, $s^{\prime}=0.1$, $c=-0.01192288639+0.01042379668 \mathrm{i}$

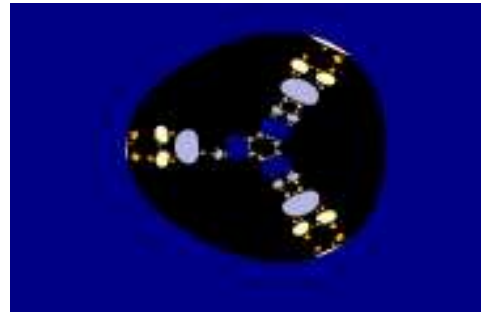

Figure 2: Relative Superior Julia Set for $s=0.5, s^{\prime}=0.4$, $c=-0.002169194079+0.0465750756 i$

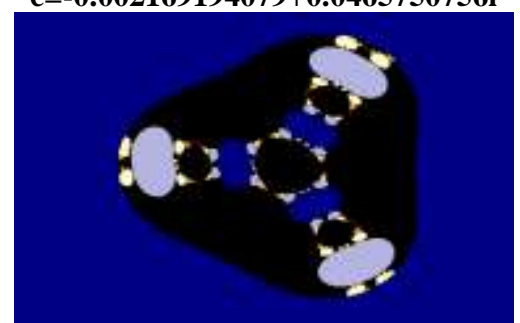

Figure 3: Relative Superior Julia Set for $s=0.8, s^{\prime}=0.4$, $c=-0.01605953579+0.01879439217 i$

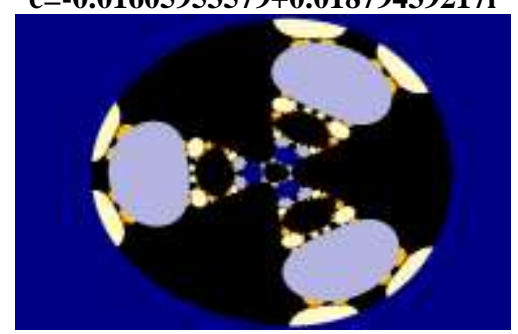

6.2 Relative Superior Julia sets for Cubic function:

Figure 1: Relative Superior Julia Set for $s=0.5, s^{\prime}=0.1$, $c=0.00888346751+0.01650347336 \mathrm{i}$

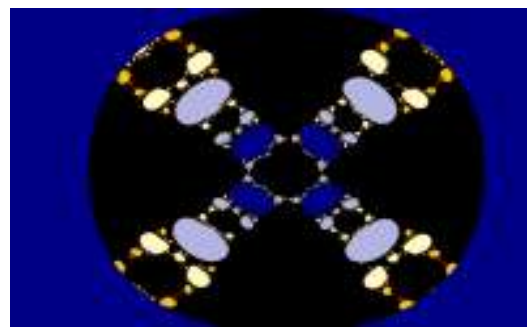

Figure 2: Relative Superior Julia Set for $s=0.5, s^{\prime}=0.3$, $c=-0.02051433067+0.012696182776 i$

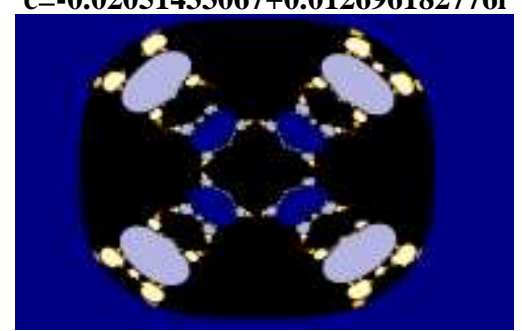


Figure 3: Relative Superior Julia Set for $s=0.8, s^{\prime}=0.3$,

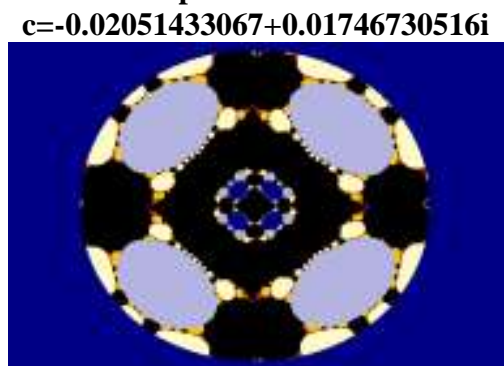

6.3 Relative Superior Julia sets for Bi-quadratic function:

Figure 1: Relative Superior Julia Set for $s=0.5, s^{\prime}=0.1$, $c=-0.01573769494+0.03678871897 i$

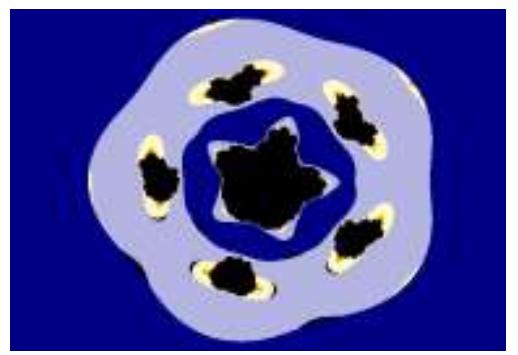

Figure 2: Relative Superior Julia Set for $\mathrm{s}=\mathbf{0 . 5}, \mathrm{s}^{\prime}=\mathbf{0 . 3}$, $c=-0.0227144337+0.04376545773 i$

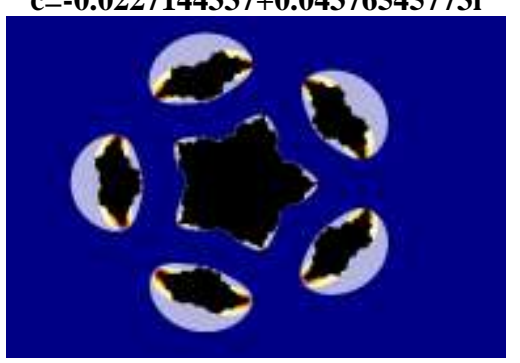

Figure 3: Relative Superior Julia Set for $\mathrm{s}=\mathbf{0 . 8}, \mathrm{s}^{\prime}=\mathbf{0 . 3}$,

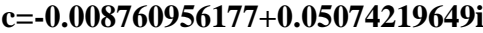

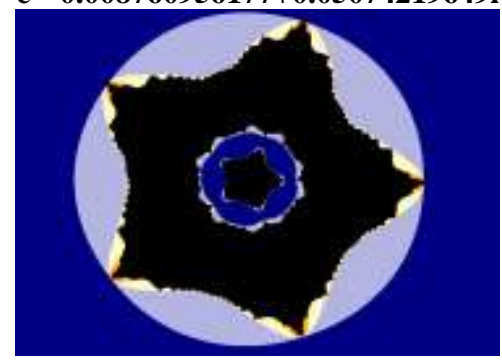

\section{CONCLUSION}

In this paper, we have considered the generalized transformation function $z \rightarrow\left(z^{n}+c\right)^{-1}$, for $n \geq 2$, and mathematically analyzed the visual characteristics of the fractal images in the complex $z$ and $c$ planes respectively. Relative Superior Mandelbrot of inverse function showed lace like structures with multicolored small circles. Geometrical analysis of the Relative Superior Julia sets of inverse function shows that the boundary of the fixed point region forms a $(n+1)$ hypocycloid. The geometry of Relative Superior Mandelbrot and Relative Superior Julia sets of inverse function showed their rotational as well as reflection symmetry. One of the most fascinating results is the central planet with satellite like structures obtained for biquadratic Relative Superior Julia sets.

\section{REFERENCES}

[1] B. Branner, The Mandelbrot Set, Proceedings of Symposia in Applied Mathematics39 (1989), 75105. Published as Chaos and Fractals: The Mathematics Behind the Computer Graphics, ed. R. L. Devaney, L. Keen.

[2] P. Blanchard, Complex Analytic Dynamics on the Riemann Sphere, Bulletin of the American Mathematical Society 11, 1 ( 1984), 85-141.

[3] S. Dhurandar, V. C. Bhavsar and U. G. Gujar, "Analysis of z-plane fractal images from $z \leftarrow z^{\alpha}+c$ for $\alpha<0$, Computers and Graphics 17, 1 (1993), 89-94.

[4] U. G. Gujar and V. C. Bhavsar, Fractals from $z \leftarrow z^{\alpha}+c$ in the Complex c-Plane, Computers and Graphics 15, 3 (1991), 441-449.

[5] U. G. Gujar, V. C. Bhavsar and N. Vangala, Fractals from $z \leftarrow z^{\alpha}+c$ in the Complex $z^{-}$ Plane, Computers and Graphics 16, 1 (1992), 45-49.

[6] E. F. Glynn, The Evolution of the Gingerbread Man, Computers and Graphics 15,4 (1991), 579582.

[7] S. Ishikawa, "Fixed points by a new iteration method", Proc. Amer. Math. Soc.44 (1974), 147150.

[8] K. W. Shirriff, "An investigation of fractals generated by $z \rightarrow z^{-n}+c^{\prime \prime}$, Computers and Graphics 13, 4 (1993), 603-607.

[9] B. B. Mandelbrot, The Fractal Geometry of Nature, W. H. Freeman, New York, 1983.

[10] H. Peitgen and P. H. Richter, The Beauty of Fractals, Springer-Verlag, Berlin, 1986.

[11] C. Pickover, Computers, Pattern, Chaos, and Beauty, St. Martin's Press, NewYork, 1990.

[12] R. Rana, Y. S. Chauhan and A. Negi, Non Linear dynamics of Ishikawa Iteration, In Press, Int. Journal of Computer Application (Oct. 2010 Edition).

[13] S. T. Welstead and T. L. Cromer, Coloring Periodicities of Two-dimensional Mappings, Computers and Graphics 13, 4 (1989), 539-543. 